\title{
تقييم كتاب تعليم اللغة العربية بجامعة سونان كونونج جاتي الإسلامية الحكومية باندونج إندونيسيا
}

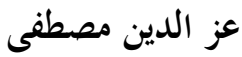 \\ مدرس جامعة سونان غونونج جاتي الإسلامية الحكومية باندونج
}

Email: izzuddinmusthafa@yahoo.com

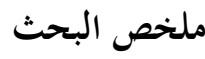

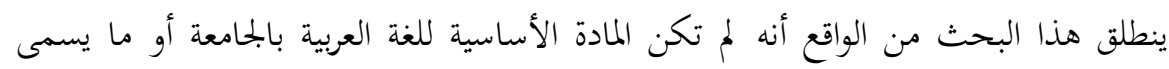

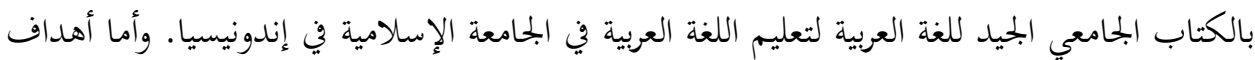
البحث فتتلخص في: 1) التعرف على مواصفات الكتاب الجامعي للغة العربية المستخدم حاليا في

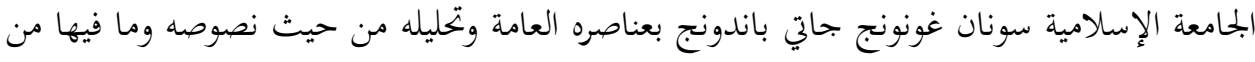

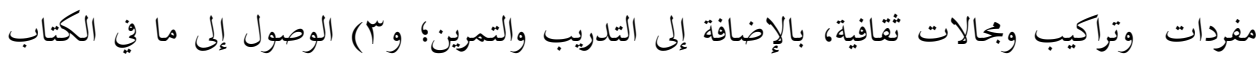
من إيجابيات وسلبيات بغرض تحسينه وتطويره. والطريقة المستخدمة هي الطريقة الوصفية التحليلية

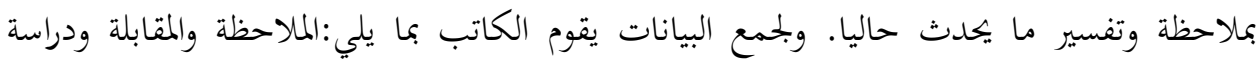

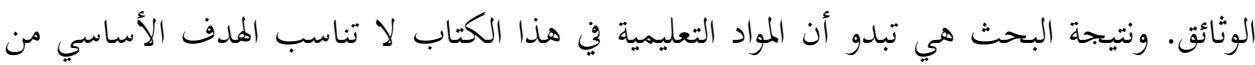
تعليم اللغة العبية في هذه الجامعة لإغفال مهارتي الاستماع والكلام والميل كثيرا إلى مهارة القراءة والكتابة فقط. المصطلحات الرئيسية: التقييم، كتاب التعليم، اللغة العربية، الجامعة

\section{ABSTRACT}

This study departed from the reality that until now has not found an Arabic teaching material both in Universities. The purpose of this study is 1) to determine the characteristics of teaching materials that have been used in UIN SGD Bandung; 2) to develop the Arabic language teaching materials more relevant to UIN SGD Bandung. The method used in this research is descriptive analytic method. The technique used for collecting data are observation, interview and literature study. From the results of this study concluded that the teaching materials used in UIN SGD Bandung is not relevant to the purpose of learning Arabic in UIN SGD Bandung, because Arabic teaching materials tend to be more concerned with writing skills and reading and ignoring the listening and speaking skills.

Keywords: Evaluation, Teaching Materials, Arabic Language, Islamic University 
إن اللغة معيار يقاس به مدى تقدم حضارة أمة من الأمم. والأمة المتقدمة تهتم بلغتها وتحرص كل الحرص على تطويرها ونشرها خارج نطق المتكلمين بها حتى تستطيع أن تنشر ثقافتها وحضارتا بين

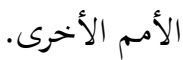

واللغة تلعب دورا هاما في حياة الإنسان لأهما وسيلة الاتصال من بني جنسه وأداة للتفاهم بين الأفراد والجماعات في المواقف الحيوية التي تتطلب الكالام والاستماع والكتابة أو القراءة وهي كذلك من وسائل الارتباط الروحي بين أفراد البحتمع المعين.

اللغة العربية هي لغة التواصل بين المسلمين في مختلف نواحي الأرض، ولغة موحدة بينهم تستخدم في المنظمات العالمية الإسلامية كرابطة العالم الإسلامي وغيرها بل أها أصبحت لغة رسمية في

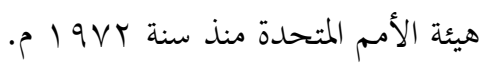
كما أها لغة القرآن الكريم والحديث الشريف ولغة التراث والفكر الإسلامي لأجل ذلك عني بها العلماء والدارسون وصرفوا هتهم إليها وبذلوا جهودهم لنشرها.

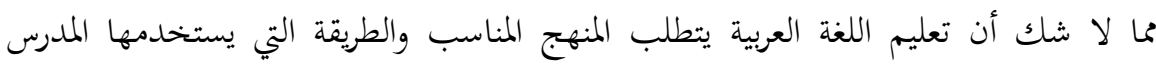
والوسائل التعليمية والكتاب الملائم لعملية التعلم والتعليم.

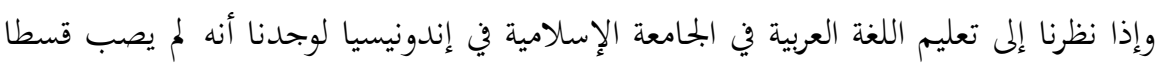
كبيرا من غرضه المنشود لعدم توافر الوسائل المعينة على تعليمها. من أهم مشاكل تعليم اللغة العربية في الجامعة الإسلامية في إندونيسيا عدم وجود المادة الأساسية للغة العربية بالجامعة أو ما يسمى بالكتاب الجامعي الجيد للغة العربية.

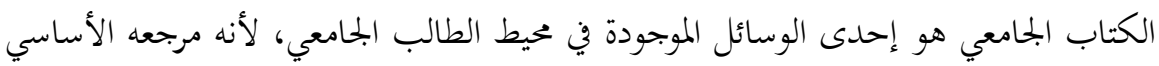
الذي يعتمد عليه إثراء معارفه وخبرته، ويرجع إليه في المذاكرة والامتحان باعتباره سجلا مطبوعا وليس قولا مسموعا، فإنه بلا شك سيؤثر فيه ليس في جانب واحد فقط وإنما في جوانب مختلفة من شخصيته فهو يقرأه ويتأثر بما فيه من آراء وأفكار، ويحتفظ به ليعود إليه كلما أراد، ويقرأه كلما أحب، ويرجع إليه في كل لحظة إذا أدركه النسيان لتذكر حقيقة من الحقائق أو حادثة من الحوادث أو معرفة من فئن المعارف ولذا فالكتاب الجامعي ليس بحرد وسيلة معينة على التعلم فقط في بعضها الآخر للإفادة بما في هذه الكتب من خبرات ومعلومات بالنسبة للمعلم والمتعلم على حد سواء. وأما الأهداف العلمية فتتلخص في: (1) التعرف على الكتاب الجامعي للغة العربية المستخدم 
Izzudin Musthafa

حاليا في الجامعة الإسلامية سونان غونونج جاتي باندونج بعناصره العامة؛ ؟) تحليل المادة الأساسية

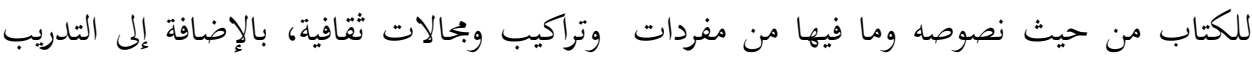

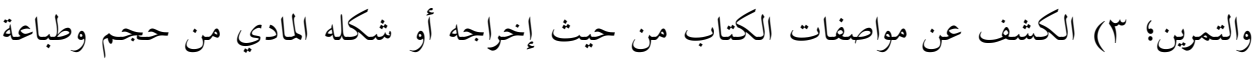

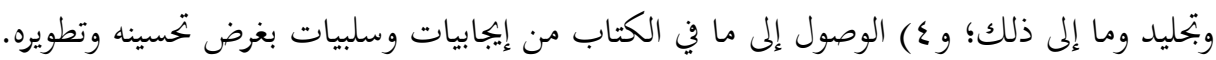

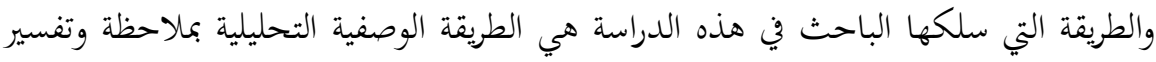

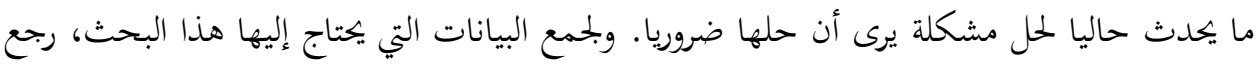

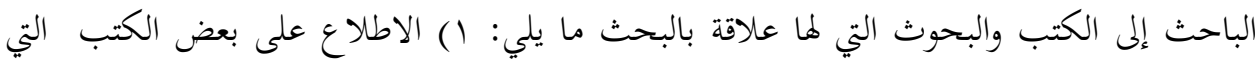

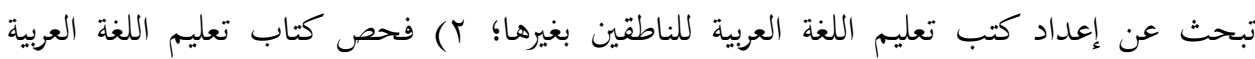

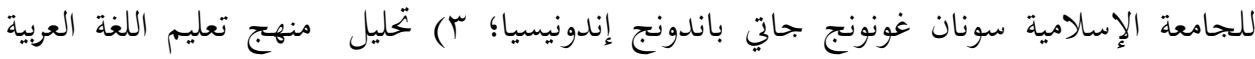

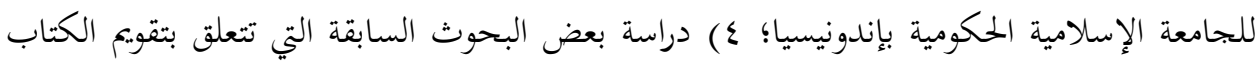
المدرسي لاسيما تقويم كتاب اللغة العربية للناطقين بغيرها. أما حدود هذا البحث فتقتصر على نفس الكتاب المذكور من حيث عناصره العامة ومادته

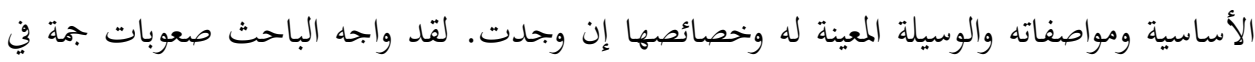

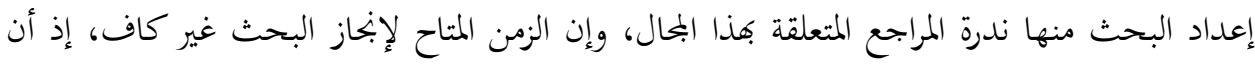

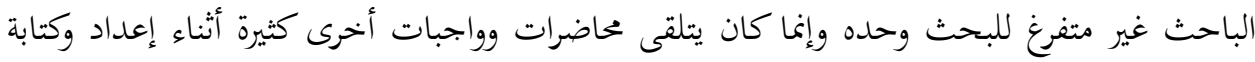

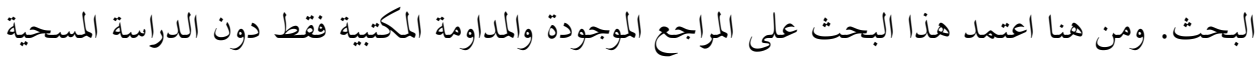
أو المقابلة بسبب بعد المسافة بين السودان وإندونيسيا.

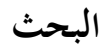

\section{مفهوم الكتاب المدرسي}

الكتاب المدرسي هو أقدم الوسائل التعليمية وأهما على الإطلاق فهو بمثابة المرشد والمرجع لكل

من المعلم والمتعلم.وفيه تحدد أهداف المادة وطرائق تعليمها وفيه يشار إلى (الأساليب التربوية المتبعة) والوسائل التربوية المرافقة (محمود إسماعيل صيني ومحمد علي القاسمي: ـ191 (1).

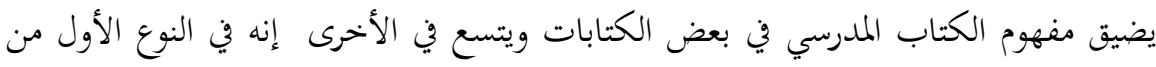
هذه الكتابات يقتصر على الشكل التقليدي للكتاب الذي يوزع على الطلاب، وهو في فئ النوع الآخر

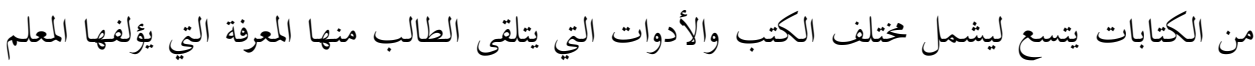

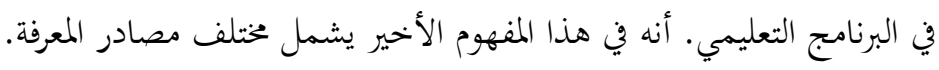


والكتاب المدرسي في الدراسة الحالية يعني: ذلك الكتاب الذي يشمل على بحموعة من المعلومات الأساسية التي تتوخى تحقيق أهداف تربوية محددة سلفا. (معرفية Cognitive أو وجدانية Affective إن المنطلق الذي تتبنا هذه الدراسة هو أن ثمة فرق بين الكتاب المدرسي بمفهومه الضيق وبين المواد التعليمية Teaching Materials بمفهومها الواسع (محمد كامل الناقة ورشدي محمد طعيمة، $\cdot(r \cdot: 19 \wedge r$ إن الكتاب المدرسي في علمنا المعاصر لا يعد بجرد وسيلة من وسائل التعليم العادي فحسب، وإنما هو أداة من أهم أدوات التعليم في عصر لم تكن للعلم فيه حدود معينة أو آفاق محددة، وإنما هو عصر قد اتسم بتفجر المعرفة وانتشار التعليم. وتقدم المعارف والعلوم في كل بحال من بحالات الحياة، الأمر الذي جعل من الكتاب بعامة والمدرسي منه بخاصة، ومادته المقروءة ركيزة أساسية من ركائز التقدم والتطور في بحتمع من البحتمعات. إنه من تطور المحتمعات وتقدم العلم والتكنولوجيا وتنوع وسائل النشر والإعلام وتعدد الاختصاصات، أصبحت الحاجة ماسة إلى المادة التعليمية المكتوبة والمقروءة للحد من التفاعل المباشر بين التلميذ ومعلمه من جهة، وبين عمليات الاعتماد الكلي على المعلم في التعليم، وتشجيع عملية التعليم الذاتي لدى المتعلم من جهة أخرى. إن الكتاب المدرسي وإن لم يكن كما كان في الماضي الأساس الأول في عملية التعليم والتعلم إلا أنه لا يزال إلى يومنا هذا أداة رئيسة في عملية التدريس، حيث يستخدمه المعلم في تخطيط عمله التدريسي قبل الشروع بتنفيذه، وفي أثناء عملية التنفيذ ليثير انتباه تلاميذه ويمكنهم من الفهم، وفي المراحل الأخيرة من درسه لتعزيز التعلم تثبيت المعلومات. وهو بهذا سيظل عنصرا جوهريا في العملية

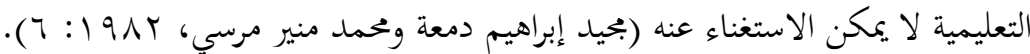
إن الكتاب المدرسي وإن لم يستطع وحده أن يؤدي جميع الوظائف التعليمية المطلوبة منه إلا إذا توافرت فيه طائفة من الخصائص والشروط المعينة، فهو لا يزال أداة مهمة من أدوات التعليم بيد المعلم، ويستطيع أن يستفيذ هو تلاميذه مما فيه من معلومات وأفكار لأهفا تكون أساسا مشتركا لدراسة

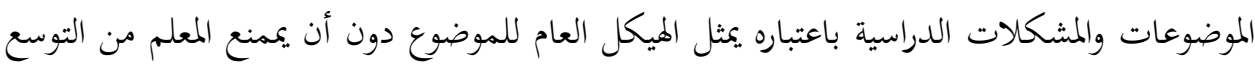
في غيره من الكتب والمراجع. إن الأهم من كل ما تقدم هو أن مدارسنا تتبنى في برابحها التعليمية منذ مدة طويلة وسوف 
Izzudin Musthafa

تظل على هذا المنهج إلى زمن غير معروف نوعا من المناهج يسمى "مناهج المواد المنفصلة". وتقضى طبيعة هذه المناهج أن يؤلف لها كتاب مدرسي خاص يغطي جميع مفرداتا التي تتخذ عادة صورة المقررات يعتمد لكل واحد منهارسميا كتاب معين ينبغي لطلابنا أن يدرسوه ويتعلموا أو يجفظوا ما فيه من معلومات ضمانا لنجاحهم في الامتحانات المدرسية وامتحانات فهاية العام والامتحانات الرسمية في فاية المرحلة الدراسية (بحيد إبراهيم دمعة ومحمد منير مرسي، ب 91 | V V). فالكتاب المدرسي إذن بالنسبة لهذا النوع في تنظيم المناهج هو الأداة الأساسية لتنفيذها في المدارس وبالتالي، فهو وسيلة لا يمكن أن يستغني عنها لدراسة هذه المواد المنفصل بعضها عن بعض لنجاحه وتقدمه في مراحل الدراسة وهو أيضا وسيلة لا يمكن للمعلم أن يستغني عنها تطبيقا للمنهج وتنفيذا لمفرداته.

مواصفات الكتاب المدرسي وعلاقته بالمنهج

() لما كان المقرر الدراسي لأية مادة من مواد التعليم في المدارس بعد تفصيلا وتطبيقا لأهداف المنهج، فإن على الكتاب المقرر لتلك المادة، أن يكون كتابا ملائما يأحذ في اعتباره جميع أقسام ذلك المقرر التي يتطلب تعليمها وتعلمها ومن قبل التلاميذ على نحو أفضل. Y ألا يكون الكتاب المدرسي الجيد، مقصورا بمادته ومحتوياته على تغطية مفردات المنهج المقرر وحدها، أو على الحقائق والمعلومات النظرية المحردة المطلوب دراستها من قبل التلاميذ ضمانا لنجاحهم في الامتحان فقط، وإنما يجب أن يعني الكتاب المدرسي الجيد بتوفير فرص كافية ومتعددة للتلاميذ ينمون فيها ميولما واتحاهاةم، ويشبعون بها حاجاةم ورغباةم، ويتربون على ألى بعض المهارات والعادات الأساسية التي شاها أن تساعد على التصرف باتزان وتعقل حيال مواقف الحياة المختلفة، وتمكنهم من الاندماج والانسجام بيئتهم المحلية انسجاما طبيعيا يمكنهم من حل مشكلامتم العامة، ويؤهلهم للمساهمة في حل مشكلات بحتمعهم بطريقة عملية إلى جانب ما يتعلمونه في ذلك من حقائق ومعارف ومعلومات. ץ) أن يوفر الكتاب المدرسي الجيد لدراسيه، في أية مرحلة من المراحل الدراسية، فرصاكافية لأن يربطوا من معلومات جديدة بما يعرفونه من معلومات سابقة، بحيث تصبح دراستهم للمادة الموجودة في هذا الكتاب دراسة متكاملة تتسم بالعمق والتكامل والشمول المطلوب. يي ضوء العلاقة القائمة والتداخل المشترك ما بين الكتاب والمنهج ينبغي لمؤلف الكتاب قبل الشروع بتأليفه أن يطلع على "دليل تألف الكتاب" لأن هذا الدليل من شأنه أو يوجه 
المؤلف إلى التقريب بين وجهة نظره ووجهات نظر المؤلفين الآخرين الذين يؤلفون المادة

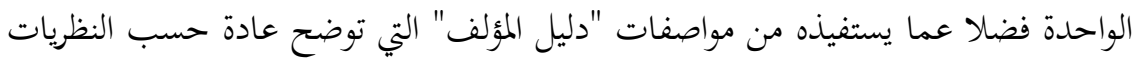

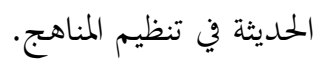
0) ملما كان الكتاب المدرسي الذي نختاره لتدريس مادة من المواد في المدارس، يعد وسيلة رئيسية

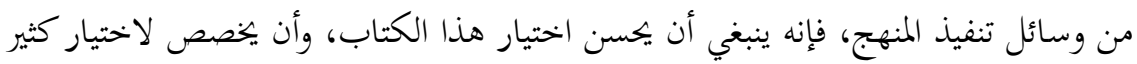

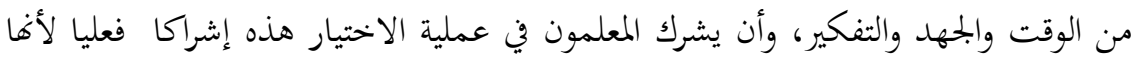

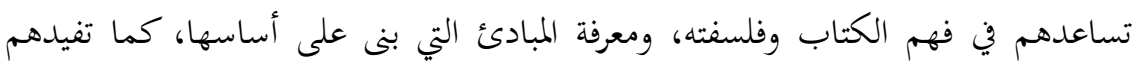

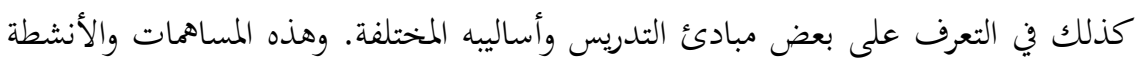

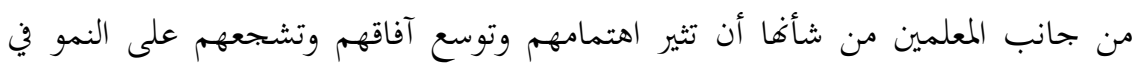

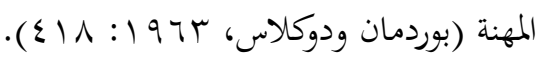
الكتاب المدرسي - كما ذكرنا - هو إحدى الوسائل المستخدمة لتطبيق المنهج ولكنه ليس المانس

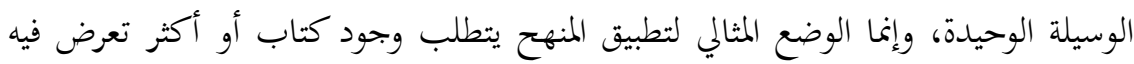

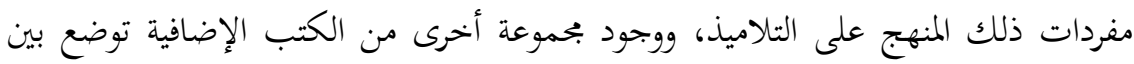

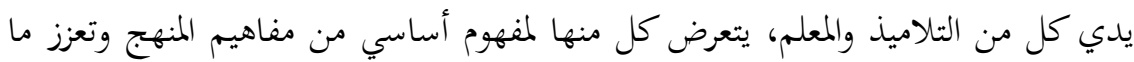

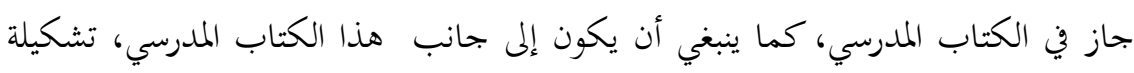

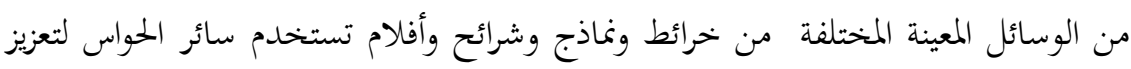

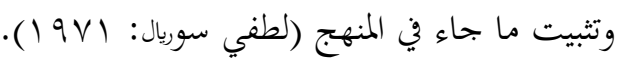

\section{تقويم كتاب اللغة العربية للجامعة الإسلامية الحكومية}

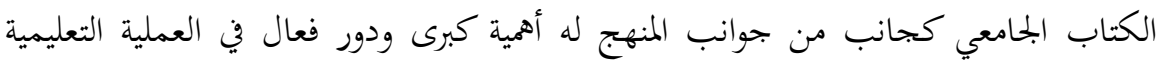

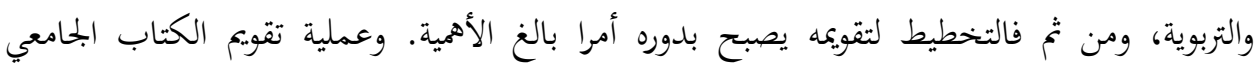

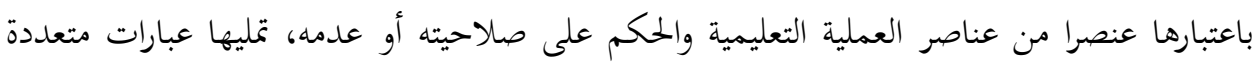

( ) إن الكتاب الجحامعي هو أداة من أدوات التعليم وهو بهذا المعنى ينبغي أن يكون جيدا وصالحا

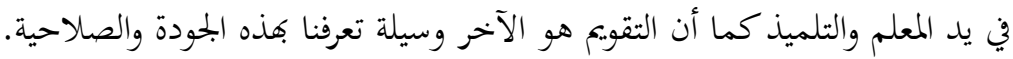

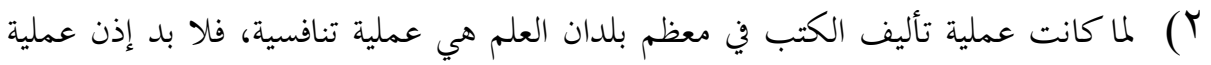
تنقية وتصفية واختيار بين هذه الكتب وليس هناك من سبيل لهذه التنقية سوى التقويم. 
Izzudin Musthafa

إن العصر الذي نعيش فيه عصر تقدم وتغير سريعين في كل بحال من بحالات العلم والمعرفة.

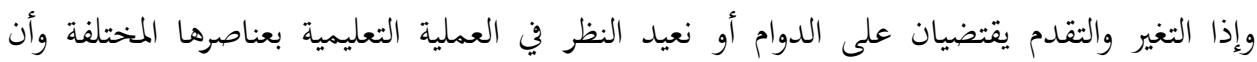

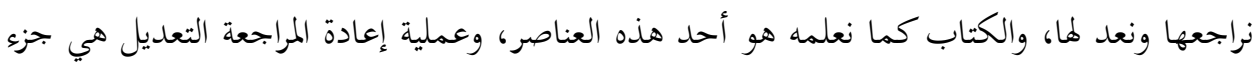

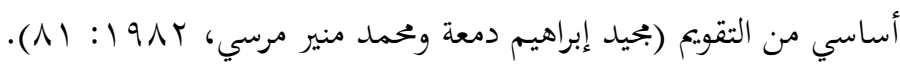

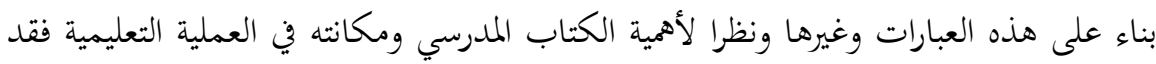

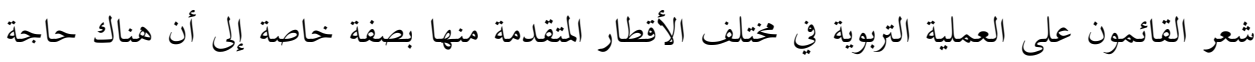

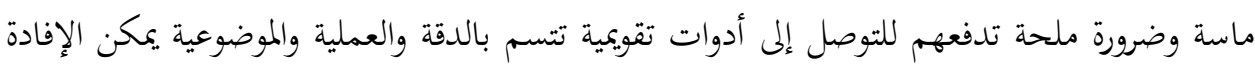
منها واستخدامها في تقويم الكتب المدرسية، ولتقويم كتاب تعليم اللغة العربية للجامعة الإسلامية سونان

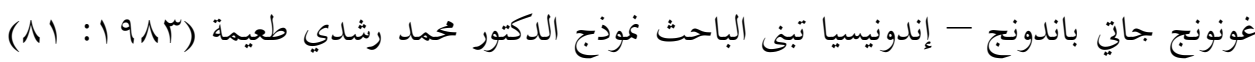

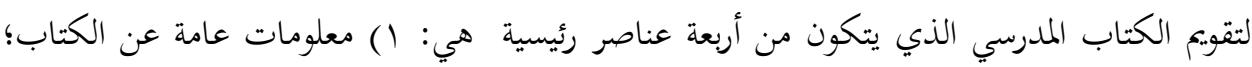

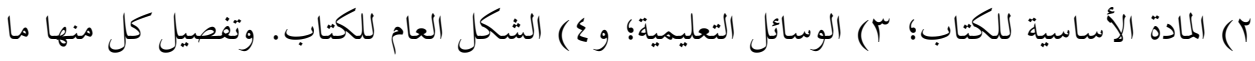

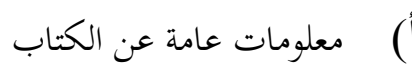

$$
\begin{aligned}
& \text { () عنوان الكتاب }
\end{aligned}
$$

عنوان الكتاب الذي يسعى هذا البحث لتقويمه يكتب باللغة العربية فهو "اللغة العربية للجامعات الإسلامية" أي أن هذا الكتاب استخدم لطاب البحاب الجامعة الإسلامية.

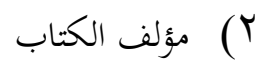

قام بتأليف الكتاب نخبة من أساتذة اللغة العربية في جامعة (سونان غونونج جاتي باندونج)

$$
\text { بتكليف المركز اللغوي في الجامعة الإسلامية نفسها. }
$$

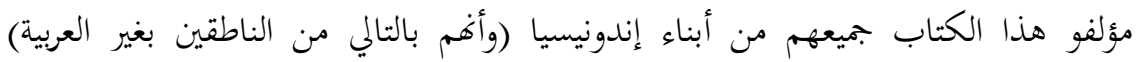

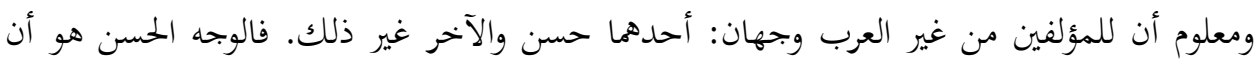

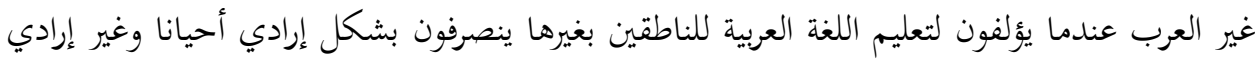

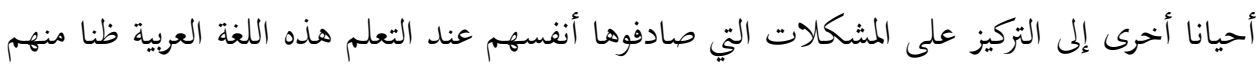

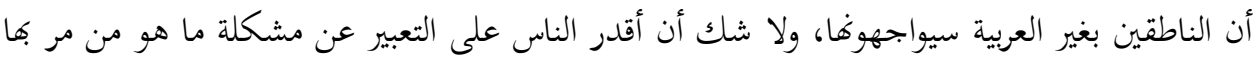
وعاني منها. 
وأما الوجه الآخر فهو غلبة الحس اللغوي الأجنبي على المؤلف مما يجعله يتعامل مع اللغة العربية بالشكل الذي يتعامل به في لغته القومية، فيضع القالب العربي في قالب أجنبي، والصياغة العربية في

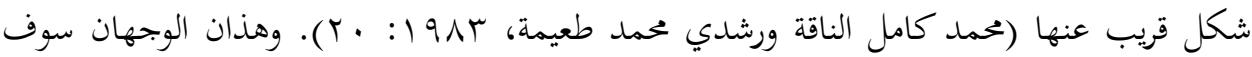
يكونان من ضمن تقويمنا لهذا الكتاب. ب) الهدف من تأليف الكتاب من صناب

ألف هذا الكتاب خصيصا لتعليم اللغة العربية في المرحلة الجامعية وما في مستواها بالجامعة الإسلامية وهو امتداد للكتاب الذي تم تأليفه لتعليم اللغة العربية في المرحلة الجحامعية. ولقد اعتمد المؤلفون في تأليفهم على منهج اللغة العربية الذي وضعته وزارة الشؤون الدينية. والهدف الأساسي من الكتاب هو تمكين الطالب من فهم الكتب العبية والقواعد العربية ولتحقيق ذلك سار المؤلفون في عرض المادة على نظرية الوحدة وهي نظرية تنظر إلى اللغة على أها وحدة مترابطة متماسكة، وليست فروعا مختلفة. يتكون الكتاب من جزئين، الجزء الأول، مقرر للفصل الدراسي الأول والجزء الثاني مقرر للفصل الدراسي الثاني. ويبلغ عدد صفحات الجزء الأول 11 1 صفحة والجزء الثاني تبلغ صفحاته

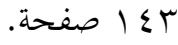

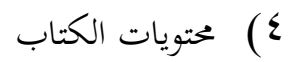
لكل من جدول المحتويات والفهرس دوره في تعريف القارئ بمضمون الكتاب وتيسير الحصول على ما يراد من معلومات أو معارف بداخله. والفهرس التحليلي على وجه الخصوص يلعب دورا كبيرا في كتب تعليم اللغات الأجنبية، ويشمل عادة على عناصر رئيسية منها رقم الدرس وعنوانه والمهارات اللغوية التي يدور حولها، والقواعد النحوية التي يتناولما والحروف التي تم تجريدها صوتا ورسما وغير ذلك من عناصر. وفي هذا الكتاب يعرض الفهرس أو جدول المحتويات عنصرين من العناصر الرئيسية المذكورة، هما رقم الدرس والعنوان الداخلي لكل درس. وبالنظر إلى عدد الدروس الموجودة في هذا الكتاب بند أن الجزء الأول من الكتاب يحتوي على • ب درسا والجزء الثاني يحتوي على ب إ درسا. أما العناوين الداخلية في هذا الكتاب فنجد أها تدور حول الموضوعات المتنوعة. ومعروف أن العناوين الداخلية تستمد أهميتها من حقيقة أها مشير يدل على محتوى الدروس التي تدور حولها، شخصا كان أو ملمحا ثقافيا أو موقفا من مواقف الحياة اليومية. 
Izzudin Musthafa

0) عناصر الكتاب

يشتمل الدرس بشكل عام في ثانيا الكتاب على ثلاثة عناصر رئيسية، هي:

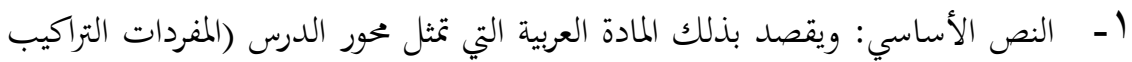

والجمل التي يرجى تعليمها للتلاميذ).

r- القواعد النحوية: ويقصد بذلك إخراج المفاهيم اللغوية والصرفية من النص السابق لتبلاميل).

وشرحها شرحا وافيا مع إعطاء القاعدة لما والأمثلة المتعلقة بها.

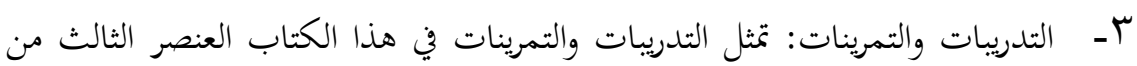

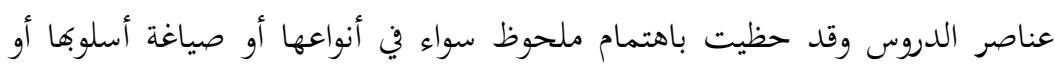

اختيار المهارات التي تنميها.

$$
\text { طرق التدريس }
$$

الكتاب المدرسي يحدد طريقة التدريس أو يوحي بها والمدرس لا يملك إلا أن يتأثر بطرق التعليم

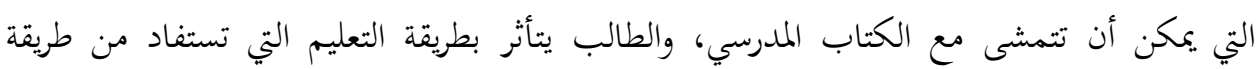

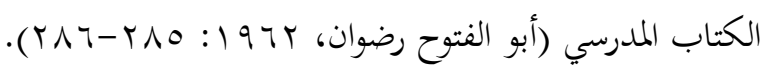

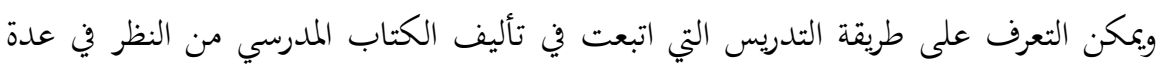

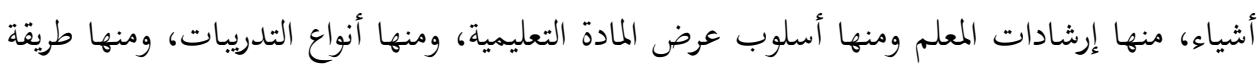
تقديم المفاهيم اللغوية والقواعد الإملائية.

أما الطريقة التي اتبعت في هذا الكتاب فنجد أن الطريقة المستخدمة هي طريقة القواعد والترجمة

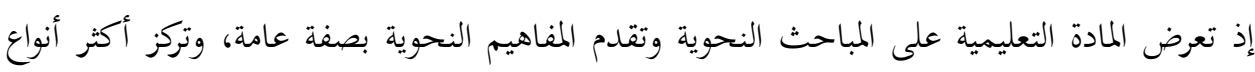

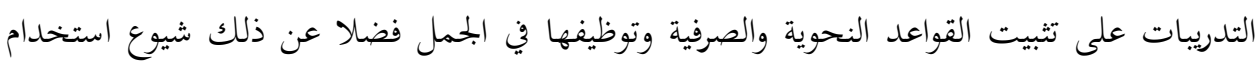
اللغة الوسيطة في تعليمات كل عناصر الدرس وشرح معنى الكلمات وتوضيح المفاهيم النحوية والصرفية.

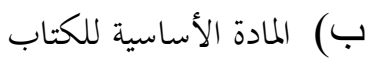

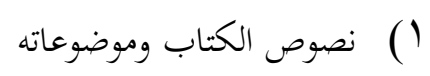

ذكرنا في أن طريقة الكتاب في عرض المادة التعليمية تستند إلى نظرية الوحدة التي تتخذاته

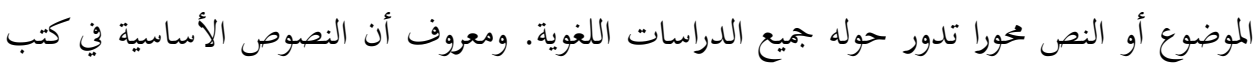
تعليم اللغات الأجنبية تعرض في شكل الحوار أو في شكل النثر العادي إلا أن الميل في أغلب الأحيان

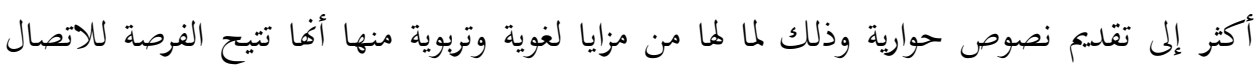


اللغوي واستخدام أنواع الجمل الحبرية والاستفهامية والتدريب على أنواع النبر والتنغيم في السؤال

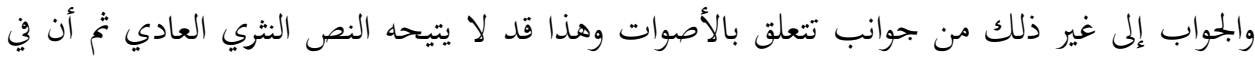

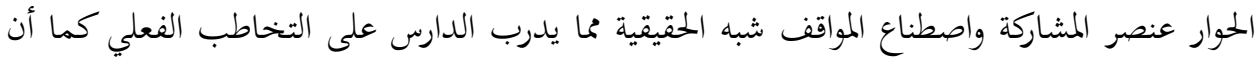

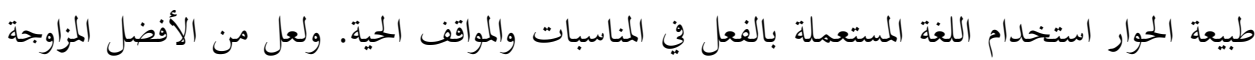

$$
\begin{aligned}
& \text { بين النصوص الحوارية والنصوص الثرية. } \\
& \text { ب بان الغة الكتاب ومفرداته }
\end{aligned}
$$

المادة اللغوية هي إحدى المقومات الرئيسية أو إحدى الأركان الأساسية في تعليم اللغة العربية

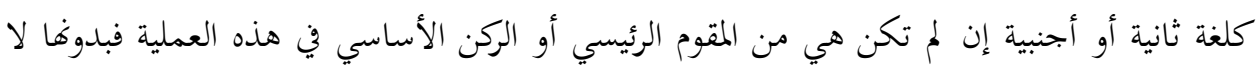

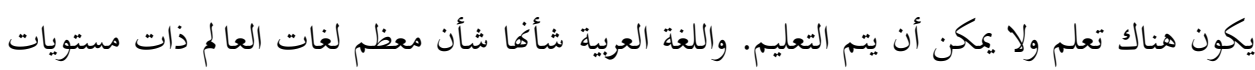

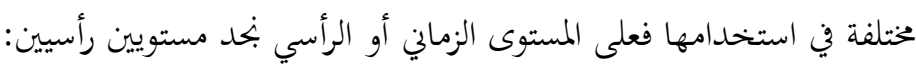

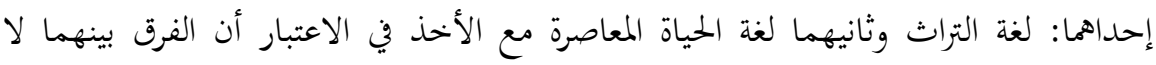

$$
\text { يصل إلى حد اعتبار إحداهما غريية عن الأخرى. }
$$

وعلى المستوى المكاني أو الأفقي بند مستويات متمثلة في لهجات محلية تختلف في بلد عربي

عن الآخر.

واللغة العربية كغيرها من اللغات تتكون من نظم اللغة الثلاثة وهي نظام النطق نظام المفردات

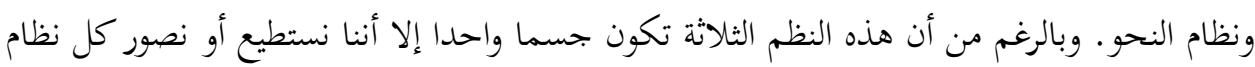
منفصلا عن الآخر.

وإذا لاحظنا اللغة المستخدمة في هذا الكتاب بند أهما قدمت في شكل اللغة المستعملة في

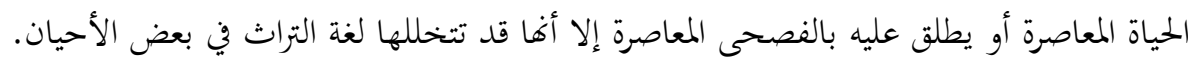

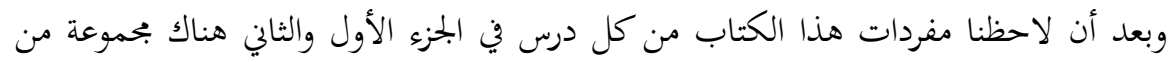
الملاحظات العامة برزت من خلال التحليل تتصل بالمفردات يجدر هنا ذكرها كما يلي:

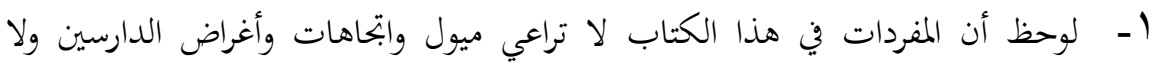

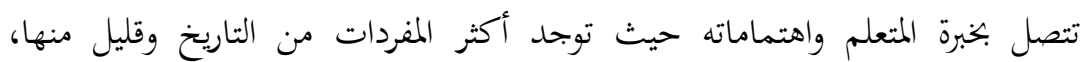

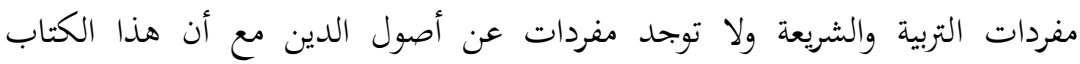

$$
\text { استخدم في كلية أصول الدين والتربية والشريعة والدعوة. }
$$


Izzudin Musthafa

r- لا تثير بعض المفردات الرغبة في تعلم الثقافة العربية الإسلامية حيث توجد بعض الدروس

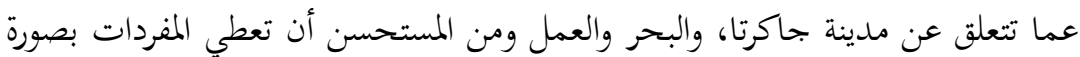
صادقة عن الحياة في البلدان العربية.

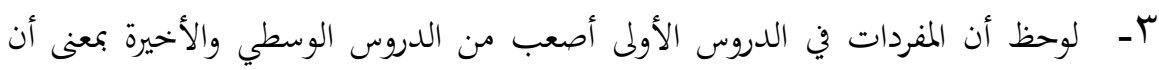

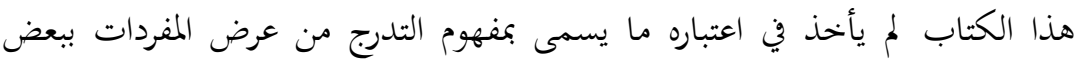

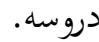

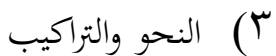

أن النحو عنصر من العناصر المكونة للغة وأنه في بعض طرق تعليم اللغات يمثل الأساس الأول

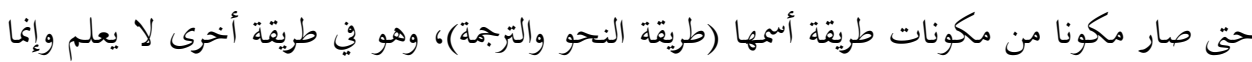

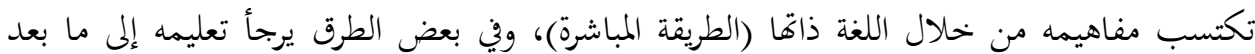
مستوى المبتدئين (السمعية الشفوية)، وهكذا تتفاوت مكانة النحو في طرق تعليم اللغات الأجنات النبية. والكتاب المقوم هذا ليس كتابا في النحو أو كتابا لتدريس النحو العربي البحت وإنما هو كتاب

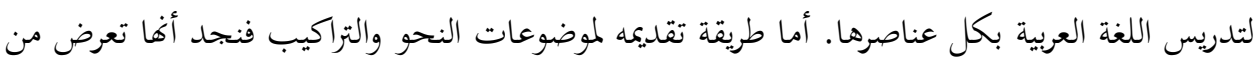
خلال النصوص الأساسية وتقديم شرحها بعد عرض النصوص الأساسية مباشرة.

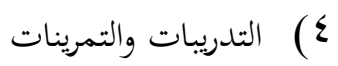

تعتبر التدريبات على الخبرات الواردة بالنصوص مسألة ضرورية لأفا تساعد المتعلم على التفاعل كما أهما تثبت الخبرات التي تعلمها وتنظيمها وتساعد على فهم محتوى الخبرة المقدمة ولكن تأثيرها

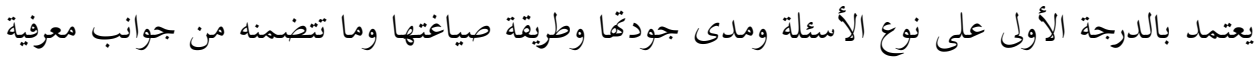
أو عقلية أو انفعالية أو وجدانية.

وقد قسم المختصون التدربيات إلى الثلاثة أقسام رئيسية وهي: التدريبات الميكانيكية والتدربيات

$$
\begin{aligned}
& \text { المعنوية والتدريبات الاتصالية (راجي محمود، 1991 1: r7 1). } \\
& \text { وفيما يلي بيان موجز لهذه التدربيات } \\
& \text { أ- أـ التدريبات الميكانيكية }
\end{aligned}
$$

همدف هذا النوع من التدريبات إلى مساعدة الدارسين على السيطرة الآلية على

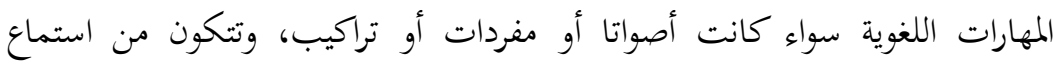


وتكرار وتصريف وتبديل وتحويل ونسخ، والصفات المميزة لهذه التدريبات هي استجابة

$$
\text { بـ- مقيدة وتعليم سلبي. }
$$

يهدف هذا النوع من التدريبات إلى تقديم المساعدة اللازمة للدارسين على استعمال المهارات اللغوية المكتسبة استعمالا محدودا وعلى نطاق ضيق. وتتكون من ربط وإكمال وصواب أم خطأ وملائمة، وسؤال - جواب من النص وتكوين أسئلة وتكوين جمل، وترجمة ومحادثة تحت إشراف المعلم وتلخيص، وإملاء والصفات المميزة لمذه

$$
\begin{aligned}
& \text { التدريبات مع استجابة مقيدة مع اختيار حر وتعليم إيبابي. } \\
& \text { ج- التدريبات الاتصالية }
\end{aligned}
$$

يهدف هذا النوع من التدريبات إلى مساعدة الدارسين على استعمال اللغة استعمالا طبيعيا حرا وعلى نطاق واسع. وتتكون من محادثة حرة ومناقشة عامة، وتدوين ملاحظات وتقارير شفوية وكتابية وإنشاء حر. والصفات المميزة لهذه التدريبات هي

$$
\text { استجابة حرة وتعليم وظيفي. }
$$

وتوجد تقسيمات أخرى للتدريبات لا يهمنا ذكرها في هذا المقام، فيسر أها تكون على مستوى المهارات اللغوية (الاستماع والحديث والقراءة والكتابة) وقد تكون مستوى العناصر اللغوية (الأصوات والمفردات والتراكيب) فالمستوى الأول يهدف إلى تمكين الطالب من المزيد من فهم واستعمال الألفاظ والعبارات الموجودة في النصوص التعليمية أما الثاني فيهدف إلى تمكين الطالب من تطبيق القواعد الصوتية والنحوية والصرفية دون تحليل نظري لهذه القواعد. هناك بحموعة من الملاحظات العامة يجدر ذكرها وهي كما يلي:

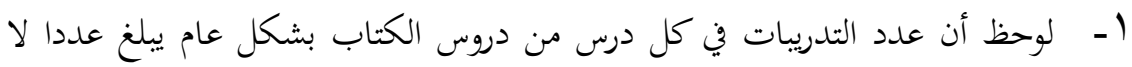

$$
\text { بأس به }
$$

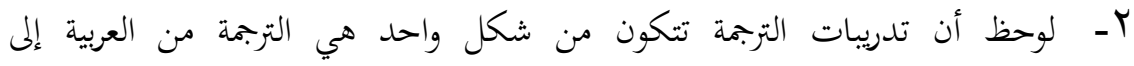
الإندونيسية وقد وردت في ع ب درسا ومن المستحسن أن تتكون الترجمة من شكلين هما الترجمة من العربية إلى الإندونيسية والترجمة من الإندونيسية إلى العربية، لتعويد الدارسين

$$
\text { على التراكيب والمفردات بالعبارات العربية. }
$$




\section{Izzudin Musthafa}

r- لوحظ أن التدريبات مثل الصواب والخطأ والمزاوجة وتركيب الجمل والقراءة وتكوين

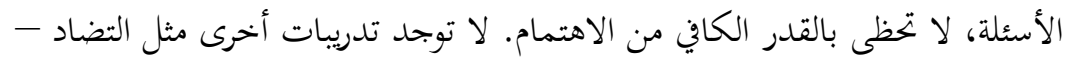

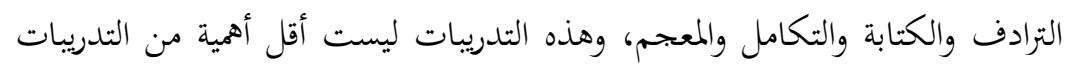
التي حظيت يقدر أكثر من الاهتمام وينبغي الالتفات إليها والاهتمام بها بشكل عامبام.

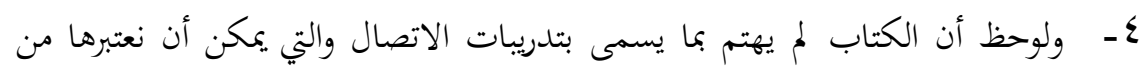

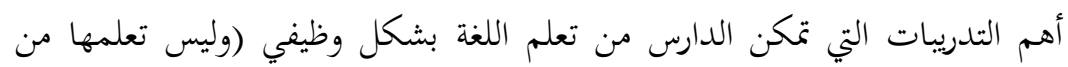

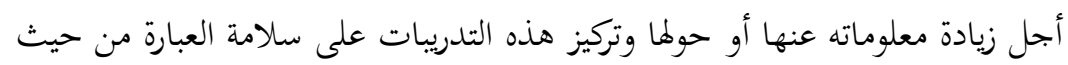

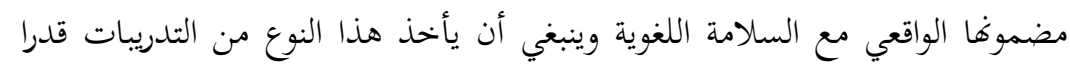
كبيرا من الاهتمام في الكتاب.

0ـ ـ كثافة تكرار المفردات في التدريب قد تؤدي إلى الملل والسأم لدى الطلبة تجاوز

$$
\text { أعمارهم من تسع عشرة سنة. }
$$

7- لا يصاحب الكتاب مفاتيح التدريبات والتمرينات وينبغي أن تكون هذه المفاتيح

$$
\text { بملاحق الكتاب. }
$$

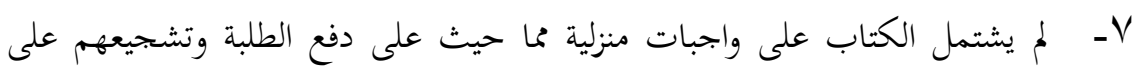

$$
\text { ج) الوسائل التعليمية التعلم الذاتي. }
$$

للوسائل لتعليمية دور هام في عملية التعليم والتعلم لأفا تحعل عملية التعليم محببة للطالب وتثير

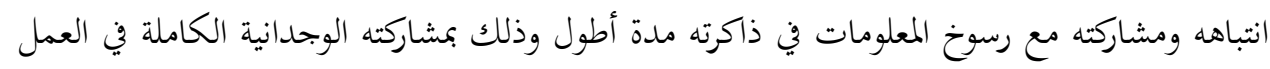
بجميع حواسه، كما بتعل وظيفة التدريس عملا سهلا يعتمد على البرامج المدرسية وعلى النظام وتقلل الجها والمعلومات.

وتحدث تلك الوسائل عادة بصورة إيضاحية في الكتاب المدرسي الجيد لتعليم اللغة العربية أما

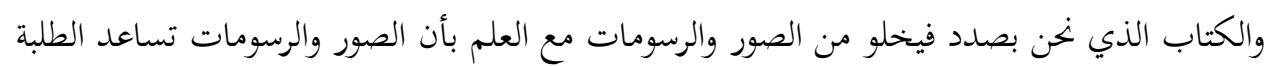
في سرعة فهم المفردات الجديدة دون الاعتماد كثيرا على الترجمة. الشكل العام للكتاب

ليس هناك أدنى شك أن الشكل العام أو إخراج الكتاب يعد من العوامل التي تدفع التلاميذ وتشوقهم إلى الدراسة. 


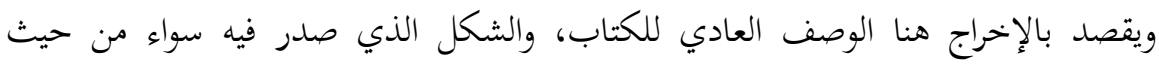

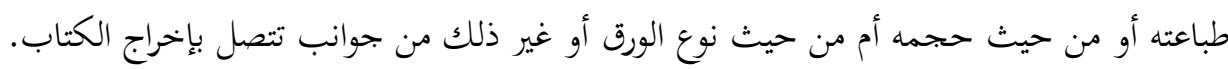

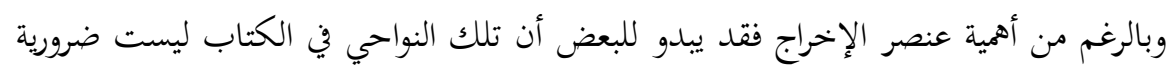

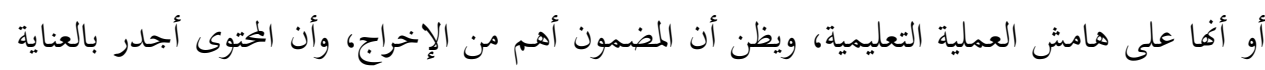

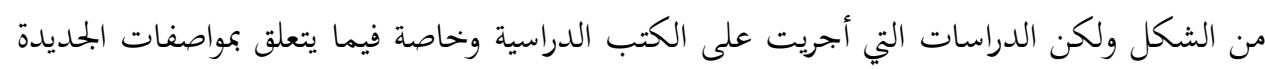

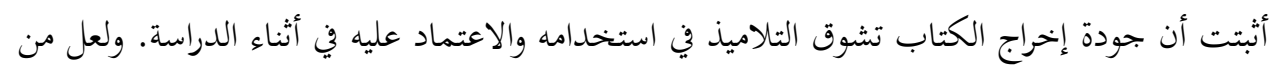

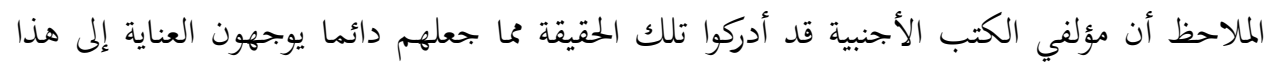

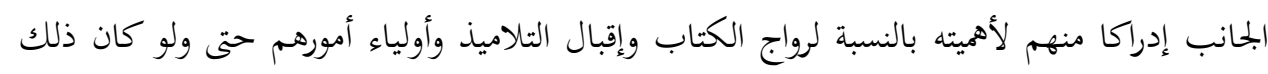

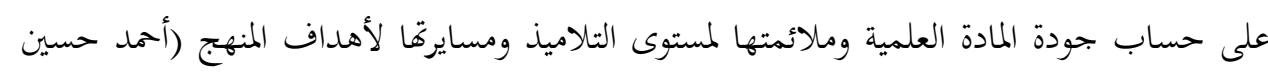

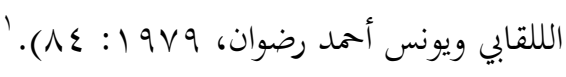

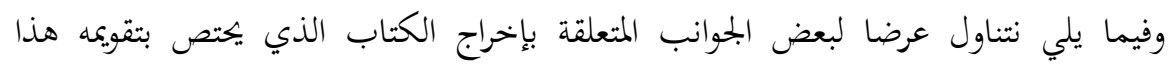
البحث:

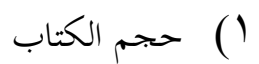

من المعلوم أن أنواع أحجام الكتب تتفاوت من الكتاب الآخر حتى كان من العسير حصر هذه

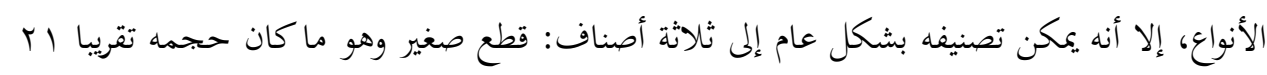

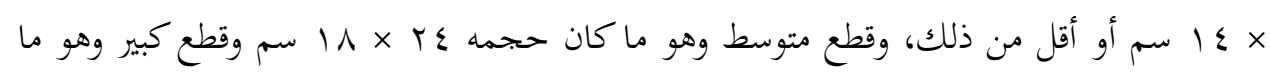

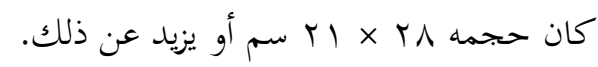

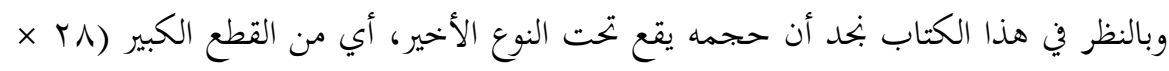

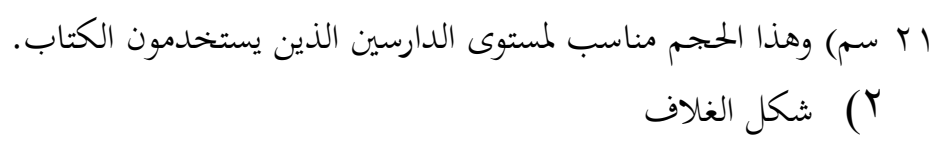

إن لمظهر الغلاف دورا كبيرا في جذب الدارسين إلى الكتاب أو صرفهم عنه، وقد يكون الغلاف مصورا كما قد يكون غير ذلك.

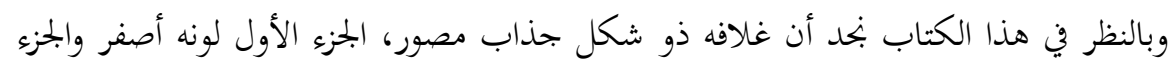
الثاني لونه أسمر كتب فيه عنوان الكتاب ومؤلفه باللون الأسود.

' أحمد حسين اللقاني ويونس أحمد رضوان. المنهج بين النظرية و التطبيق. عالم الكتب. القاهرة. 9 أو 9 . 
Izzudin Musthafa

$$
\text { ب) نوع التجليد }
$$

التجليد أنواع، منه ما هو تجليد عادي يقتصر على تدببس الكتاب خاصة إن كان قد صدر في

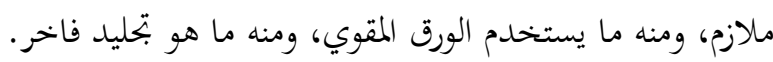

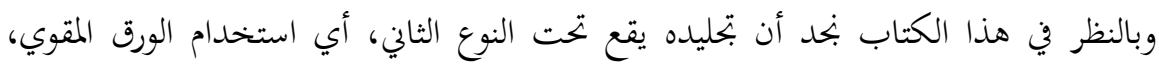
وشاع هذا الاستعمال في بتحليد الكتب لأنه أقل تكلفة وأطول بقاء.

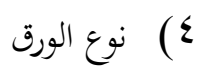

اختيار نوع الورق أيضا تحكمه اعتبارات معينة ومن أهم هذه الاعتبارات ما يتعلق عند القراءة

والورق المستخدم للكتب أنواع، منه ورق أبيض ومنه ورق مصقول ومنه ورق من نوع ورق الصحف.

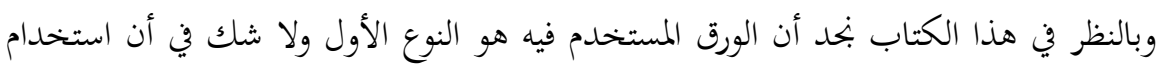

$$
\text { هذا النوع من الورق يعطي شيئا من الجاذبية للكتاب. }
$$

لحروف الطباعة أيضا دور كبير في إبحاح الكتاب وجذب القارئ، وطريقة طباعة أنواع منها ما

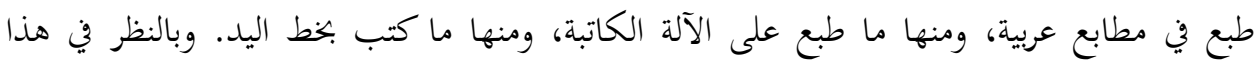
الكتاب بخد أنه طبع بخط اليد.

فالجزء الأول طبع بخط لا بأس به وأما الجزء الثاني فطبع بخط يد محسن تلمس فيه شيئا من

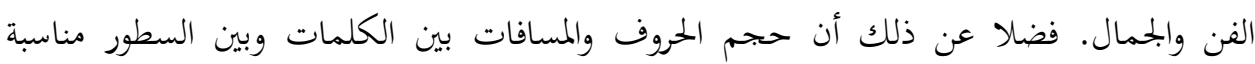
لمستوى الطلبة الذين يستخدمون هذا الكتاب.

$$
\text { الأخطاء المطبعية }
$$

إن الكتاب - رغم أنه طبعاته المتعددة لا يخلو عن الأخطاء المطبعية إذ أن الأخطاء المطبعية

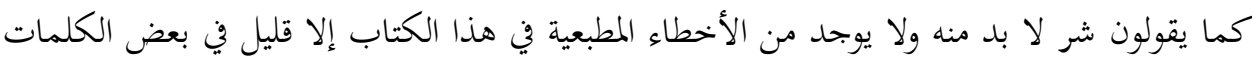

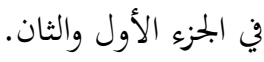

\section{النتيجة}

المواد التعليمية في هذا الكتاب لا تناسب الهدف الأساسي من تعليم اللغة العربية في هذه

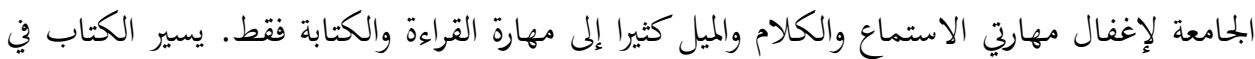

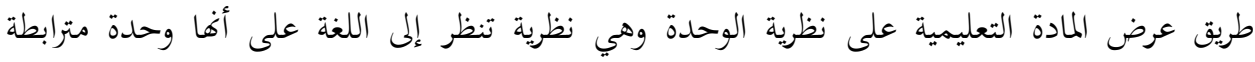


متكاملة متماسكة وليست فروعا مختلفة وهذه الطريقة مناسبة للغاية لتعليم اللغة العربية للناطقين بغيرها بما في ذلك الطلبة الذين يتعلمون اللغة العربية لأهداف خحاصة. يوصي الباحث المسئولين بأمر التعليم وزارة الشئون الدينية بإندونيسيا بتطوير كتاب تدريس اللغة العربية للجامعات الإسلامية بالتعاون مع الخبراء والمختصين العرب في حقل تعليم اللغة العربية للناطقين بغيرها. يوصي الباحث اللجنة المسئولة من أمر تطوير الكتب الجامعية للغة العربية أن تأخذ في اعتبارها نتائج هذا البحث المتواضع أثناء تطويرها لكتاب تدريس اللغة العربية للجامعة الإسلامية. يوصي الباحث اللجنة المسئولة من أمر تطوير الكتب العربية للجامعة أن تعتمد على نتائج البحوث التقابلية بين اللغة العربية واللغة الإندونيسية على جميع مستوياتها أثناء تطويرها لكتاب تدريس اللغة العربية للجامعات الإسلامية. يوصي الباحث جامعة الدول العربية المتمثلة في المنظمة العربية للتربية والثقافة والعلوم أن تساعد منظمة دول جنوب شرق آسيا، وخاصة إندونيسيا في حقل تعليم اللغة العربية وذلك بأن تمدها بالأساتذة والكتب الدراسية وغيرها.

بوردمان ودوكلاس. بד 9 ا ـ الإشراف الفني. القاهرة: مكتبة النهضة. دمعة، بحيد إبراهيم ومحمد منير مرسي. ب ب 19 ا. الكتاب المدرسي ومدى ملائمته لعمليتي التعلم والتعليم في المدرسة الإبتدائية. تونس: المنظمة العربية للتربية والثقافة. رضوان، أبو الفتوح وأخرون. باج 9 ا ـ الكتاب المدرسي. القاهرة: مكتبة الابحلو سوريال، لطفي. 99 1 ـ الكتاب المدرسي وتنفيذ المنهج. معهد التربية: أونروا يونسكو. صيني، محمود إسماعيل ومحمد علي القاسيمي. • •19 ا. السحل العلمي للندوة العالمية الأولى لتعليم اللغة العربية لغير الناطقين بها. الجزء الثاني. الرياض: عمادة شئون المكتبات. طعيمة، رشدي محمد. به19 ا. نحو أداة موضوعية لتقويم كتب تعليم اللغة العبية. المحلة العربية للدراسات اللغوية. معهد الخرطوم الدولي للغة العربية.

اللقابي، أحمد حسين وبرنس أحمد رضوان، و 9 و ـ المناهج بين النظرية والتطبيق. القاهرة: عالم الكتب محمود، راجي. 991 ـ. طريقة التدريبات الموحدة مفهومها ودورها في تدريب اللغة العربية لغير الناطقين بها، السجل العلمي للندوة العالمية الأولى لتعليم اللغة العربية لغير الناطقين بها، الجزء الثاني، جامعة الرياض: عمادة شؤون المكتبات 
Izzudin Musthafa

الناقة، محمود كامل ورشدي محمد طعيمة. ب191 ا. الكتاب الأساسي. مكة المكرمة: جامعة أم القرى.

الناقة، محمود كامل. و 19 ـ ـ أساسيات تعليم اللغة العربية لغير العرب. الخرطوم: معهد الخرطوم الدولي للغة العربية. 